\title{
Novel TLR2-binding adjuvant induces enhanced T cell responses and tumor eradication
}

\author{
Gijs G. Zom', Marian M. J. H. P. Willems², Selina Khan', Tetje C. van der Sluis' ${ }^{1}$, Jan Willem Kleinovink',
} Marcel G. M. Camps ${ }^{1}$, Gijsbert A. van der Marel ${ }^{2}$, Dmitri V. Filippov ${ }^{2}$, Cornelis J. M. Melief ${ }^{1,3}$ and Ferry Ossendorp ${ }^{1 *}$

\begin{abstract}
Background: Ligands for the Toll-like receptor (TLR) family can induce activation of cells of the innate immune system and are widely studied for their potential to enhance adaptive immunity. Conjugation of TLR2-ligand Pam3CSK4 to synthetic long peptides (SLPs) was shown to strongly enhance the induction of antitumor immunity. To further improve cancer vaccination, we have previously shown that the novel TLR2-L Amplivant (AV), a modified Pam3CSK4, potentiates the maturation effects on murine DCs. In the current study, we further assessed the immunological properties of AV.

Methods: Naïve mice were vaccinated with a conjugate of either Pam3CSK4 or AV and an SLP to assess specific $T$ cell priming efficiency in vivo. The potency of AV and Pam3CSK4, either as free compounds or conjugated to different SLPS, to mature murine DCs was compared by stimulating murine dendritic cells overnight followed by ELISA and flow cytometry analysis. Murine tumor experiments were carried out by vaccinating mice carrying established HPV16 E6 and E7-expressing tumors and subsequently analyzing myeloid and lymphoid cells infiltrating the tumor microenvironment. Furthermore, tumor outgrowth after vaccination was monitored to enable comparison of the efficiency to induce antitumor immunity by Pam3CSK-SLP and AV-SLP conjugates. To enhance therapeutic efficacy, AV-SLP conjugate vaccination was combined with ablative therapies to assess whether synergism between such therapies would occur.
\end{abstract}

Results: SLPs conjugated to AV induce stronger DC maturation, in vivo T cell priming and antitumor immunity compared to conjugates with Pam3CSK4. Interestingly, AV-SLP conjugates modulate the macrophage populations in the tumor microenvironment, correlating with a therapeutic effect in an aggressive murine tumor model. The potency of AV-SLP conjugates in cancer vaccination operates optimally in combination with chemotherapy or photodynamic therapy.

Conclusion: These data allow further optimization of vaccination-based immunotherapy of cancer by use of the improved TLR2-ligand Amplivant.

Keywords: Toll-like receptor 2, Adjuvant, Cancer vaccine, Peptide vaccination, T cell activation

\footnotetext{
* Correspondence: f.a.ossendorp@lumc.nl

'Department of Immunohematology and Blood Transfusion, section

Tumorimmunology, Leiden University Medical Center, Leiden, The

Netherlands

Full list of author information is available at the end of the article
}

(c) The Author(s). 2018 Open Access This article is distributed under the terms of the Creative Commons Attribution 4.0 International License (http://creativecommons.org/licenses/by/4.0/), which permits unrestricted use, distribution, and reproduction in any medium, provided you give appropriate credit to the original author(s) and the source, provide a link to the Creative Commons license, and indicate if changes were made. The Creative Commons Public Domain Dedication waiver (http://creativecommons.org/publicdomain/zero/1.0/) applies to the data made available in this article, unless otherwise stated. 


\section{Background}

Cells of the innate immune system can recognize pathogen-associated molecular patterns (PAMPs). These specific structures include virus-derived RNA or DNA, bacterial cell wall-derived lipoproteins or sugar groups, amongst others. The receptors of the innate immune system recognizing these structures, pattern-recognition receptors (PRRs), are classified into major receptor families, such as the Toll-like receptor (TLR) family. The latter family consists of 10 receptors in human beings and 13 in mice, which are either expressed on the cell surface or in endosomes of many antigen-presenting cells (APCs) such as dendritic cells (DCs) [1]. Triggering of TLRs by their cognate ligand generally results in activation of APCs and concomitant secretion of pro-inflammatory cytokines and upregulation of co-stimulatory molecules on the cell surface. These effects are essential in the induction of isotype class switching of $\mathrm{B}$ cells and induction of efficient $\mathrm{T}$ cell responses. Therefore, vaccinologists have extensively explored the use of several TLR-ligands as adjuvants in vaccines to prevent or treat infections and cancer [2-8].

The cell surface-expressed TLR2 can form a heterodimer with either TLR1, TLR6 or in humans also with TLR10. Binding of triacylated lipopeptides to TLR2/1 and binding of diacylated lipopeptides to TLR2/6 leads to pro-inflammatory cytokine release [1], while TLR2/10 heterodimers are thought to act as inhibitory receptors on human B cells and appear not to play a role in DCs [9]. A synthetic triacylated lipopeptide, Pam3CSK4, consisting of a central cysteine residue bound to three palmitic acid chains and a 5 amino acid long peptide $\left(-\mathrm{SK}_{4}\right)$, was shown to be a highly efficient agonist of TLR2 with a favorable solubility profile $[10,11]$.

In previous studies, we exploited the activating properties of Pam3CSK 4 by covalently conjugating the ligand to synthetic long peptides (SLPs) and studied the potential of such constructs as cancer vaccines [12-14]. Not only do Pam3CSK4-SLP conjugates mature APCs, they also have the potential to target conjugated antigens to TLR2-expressing APCs. This was exemplified by the strongly enhanced in vivo T cell priming by Pam3CSK4-SLP conjugates compared to a mixture of free Pam3CSK4 and SLP [14]. Interestingly, while the maturation of DCs by Pam3CSK4 binding was shown to be essential for efficient in vivo $\mathrm{T}$ cell priming, TLR2 itself is not the mediator in the uptake of the Pam3CSK4-SLP conjugates [12, 13]. Furthermore, we demonstrated the superiority of Pam3CSK4-SLP conjugates in the induction of antitumor immunity compared to a mixture of free Pam3CSK4 and SLP [14].

Jin et al. co-crystallized the human TLR2/1 heterodimer with Pam3CSK4 and thereby identified the residues of the receptor interacting with Pam3CSK4 [15]. We hypothesized that a hydrogen bond could be formed between the phenylalanine at position 312 of TLR1 and the lipid tail of Pam3CSK4 when a nitrogen atom would be introduced in one of the palmitic acid tails of Pam3CSK4. Indeed, we found that this improved agonist induced enhanced murine DC maturation [16]. We named this novel TLR2-L Amplivant ${ }^{\circ}$ (AV).

In the present study, we demonstrate the enhanced immunological potency of AV as an adjuvant in cancer immunotherapy. We found that AV conjugated to an SLP induced stronger in vivo $\mathrm{T}$ cell priming than Pam3CSK4 conjugated to the same SLP. This may be explained by the enhanced potency to mature APCs by AV, as AV conjugated to several distinct peptide sequences and free AV are consistently superior to Pam3CSK4 in activation of murine DCs. Moreover, anti-tumor vaccination was improved by conjugating AV to an SLP harboring a tumorspecific epitope. Combination treatments of SLP vaccination and either low-dose chemotherapy or photodynamic therapy (PDT) have been described to work synergistically $[17,18]$. PDT is based on systemic injection of a photosensitizer, followed by local tumor irradiation with a laser. We show that a combination of these tumor ablative and immunomodulatory therapies and Amplivant-SLP conjugate vaccines also acts synergistically in tumor eradication.

\section{Methods \\ Cell lines}

Tumor cell line TC-1 was provided as a kind gift by T.C. Wu (Johns Hopkins University, USA). TC-1 was generated by retrovirally transducing lung fibroblasts derived from C57BL/6 mice with the oncogenic E6 and E7 proteins of HPV16 and c-H-ras oncogenes [19]. The TC-1 cells were maintained as previously described [20]. For tumor experiments, cells with a low passage number $(<8)$ were used. The D1 cell line is a growth factor-dependent murine splenic DC cell line, showing highly similar characteristics to natural occurring DCs [21]. D1 cells were kindly provided by P. Ricciardi-Castagnoli (University of Milano-Bicocca, Italy). The B3Z hybridoma cell line was kindly provided by N. Shastri (University of California, Berkeley, USA) and cultured as described previously [22]. All cell lines were tested by PCR for rodent viruses with negative results. Mycoplasma tests routinely performed for all cell lines by PCR were negative.

\section{Peptides}

The following synthetic long peptide sequences were applied in this study, either as free peptide or conjugated to Pam3CSK4 or AV. SLP OVA CTL: DEVSGLEQLESIINFEKLAAAAAK, SLP OVA Th: ISQAVHAAHAEINEAGR; SLP $_{\text {HPV: }}$ GQAEPDRAHYNIVTFCCKCDS. Peptides were synthesized and conjugated to AV as described previously [12]. 


\section{DC maturation}

Bone-marrow derived DCs (BMDC) were isolated from C57BL/6 mouse bone marrow and subsequently cultured for 10 days as described elsewhere [21]. Either BMDC or D1 cells were incubated overnight with the indicated compounds in 96-wells culture plates. Supernatant was taken from the well after incubation, and where indicated cells were harvested and subjected to flow cytometric analysis to determine the expression of co-stimulatory markers.

\section{Transgenic OT1 T cell activation}

The $\mathrm{CD}^{+} \mathrm{T}$ cell compartment of OT1 mice fully consists of $\mathrm{T}$ cells that are specific for the SIINFEKL CTL epitope of ovalbumin. OT1 mice were sacrificed and spleen and inguinal, brachial and axillary lymph nodes were harvested to obtain OT1 T cells. A single cell suspension was made of the harvested organs using $70 \mu \mathrm{m}$ strainers (BD Biosciences) and the suspension was subsequently enriched for $\mathrm{CD}^{+} \mathrm{T}$ cells using a CD8 ${ }^{+} \mathrm{T}$ cell enrichment kit (BD). D1 cells pre-loaded for $24 \mathrm{~h}$ with the indicated constructs were washed and then co-cultured with the enriched OT1 $\mathrm{CD}^{+} \mathrm{T}$ cells $(15,000 \mathrm{DC}$ : 50,000 T cells). After $24 \mathrm{~h}$ of co-culture, $7.5 \mu \mathrm{g} / \mathrm{ml}$ brefeldin A (Sigma-Aldrich) was added and the cells were left for $16 \mathrm{~h}$ at $37^{\circ} \mathrm{C} / 5 \% \mathrm{CO}_{2}$. Intracellular cytokine staining was performed to stain IFN $\gamma$ and TNF $\alpha$ in the OT1 $\mathrm{CD}^{+}$T cells, and subsequent flow cytometry was used to determine the percentage of cytokine-positive OT1 CD8 ${ }^{+}$T cells.

\section{B3Z hybridoma activation by loading wildtype and $\mathrm{TAP}^{-1-}$ BMDC}

The B3Z cell line is a hybridoma expressing CD8 and a TCR specific for the SIINFEKL CTL epitope of OVA. Because the sequence of nuclear factor associated with $\mathrm{T}$ cell activation (NFAT) is linked to a lacZ reporter construct, a chromogenic substrate conversion can be measured at $595 \mathrm{~nm}$ wavelength upon activation of the B3Z cells. Therefore, this $\mathrm{T}$ cell hybridoma can be used to measure the level of antigen presentation by APCs independent of co-stimulatory signaling. We loaded 50,000 bone-marrow derived DCs from C57BL/6 mice and $\mathrm{TAP}^{-/-}$C57BL/6 mice per well overnight with the indicated constructs. The next day, the DCs were washed and 50,000 B3Z $\mathrm{T}$ cells were added per well for a co-culture at $37^{\circ} \mathrm{C}$. After $24 \mathrm{~h}$, the supernatant was removed and the substrate CPRG (Calbiochem) was added to all wells. A short incubation at $37^{\circ} \mathrm{C}$ revealed a color change, measurable at $595 \mathrm{~nm}$ wavelength using a microplate absorbance reader (Bio-rad).

\section{In vivo $\mathrm{T}$ cell priming}

Naïve C57BL/6 mice (Charles River Laboratories) of 6-8 weeks old were vaccinated subcutaneously in the tailbase with 5 nmole of the indicated ovalbumin-derived constructs dissolved in $50 \mu \mathrm{l}$ PBS. This dose was selected based on titration experiments conducted in earlier studies, in which we observed strong in vivo $\mathrm{T}$ cell induction [14]. Fourteen days later, an identical boost vaccination was given. Five days after the boost, all mice were sacrificed and inguinal lymph nodes and spleen were harvested. A single cell suspension of the organs was made using $70 \mu \mathrm{m}$ strainers (BD Biosciences). The cells were washed and stained with fluorescent antibodies directed against CD3 and CD8 (eBioscience), tetramers specific for the SIINFEKL CTL epitope, and 7-AAD to exclude dead cells, either directly ex vivo (LN) or after a 7-day restimulation by co-culture with irradiated OVA-expressing EG7 tumor cells (spleen). The stained cells were analyzed by flow cytometry on a FACS Calibur (BD).

Vaccination of C57BL/6 mice with the constructs derived from HPV16 E7 was performed by s.c. vaccination (5 nmole per vaccine) on day 0,14 and 23. Blood was collected on day 29 and all mice were sacrificed on day 30 to collect spleen and inguinal (draining) lymph node samples. Blood samples were analyzed for the presence of $\mathrm{D}^{\mathrm{b}}$-RAHYNIVTF tetramer-specific T cells by flow cytometry. A single cell suspension was generated of the spleens and lymph nodes using $70 \mu \mathrm{m}$ strainers to enable staining with the $\mathrm{D}^{\mathrm{b}}$-RAHYNIVTF tetramer and antibodies specific for CD3, CD8, CD62L, CD127 and KLRG1 [20]. The stained cells were analyzed by flow cytometry on a FACS Calibur (BD).

\section{Tumor outgrowth}

Naïve C57BL/6 mice (Harlan Laboratories) of 6-8 weeks old were subcutaneously challenged with 100,000 TC-1 ([19]) cells on day 0 in the right flank. On day 8, when tumors were palpable in all mice, or day 10 when indicated, a vaccination with the indicated constructs dissolved in $50 \mu \mathrm{l} \mathrm{PBS}$ was given s.c. in the tailbase. The tumor sizes were measured at least twice a week by use of a caliper. Mice were sacrificed when tumor sizes reached $2000 \mathrm{~mm}^{3}$, in accordance with Dutch animal welfare legislation.

\section{Analysis of tumor-infiltrating lymphocytes and myeloid cells upon vaccination}

Naïve C57BL/6 mice (Harlan Laboratories) of 6-8 weeks old were challenged with a TC-1 tumor as described above. On day 10 , mice were vaccinated with 5 nmole of the indicated constructs dissolved in 50ul PBS by s.c. tailbase vaccination. Tumor sizes were measured during the course of the experiment by use of a caliper. On day 19, all mice were sacrificed. Approximately $50 \mathrm{ml}$ of sterile PBS was injected intracardially to flush the blood circulation including the tumors. Tumors were accurately dissected from the mice and left in complete medium on 
ice. The tumors were subsequently cut in small pieces and mashed over $70 \mu \mathrm{m}$ cell strainers (BD Biosciences) to create a single cell suspension. Cells were washed and stained using fluorescent antibodies (eBioscience) directed against either lymphocyte or myeloid markers. Fc-block using mouse serum was added to the procedure to prevent aspecific antibody binding. Marker expression on cells was analyzed using flow cytometry (LSRII, BD Biosciences). Live myeloid cells were identified as 7-AAD ${ }^{-} \mathrm{CD}^{-} \mathrm{CD}^{-11 \mathrm{~b}^{+}}$. Within this gate, several subpopulations were identified as described in the Results section and Fig. 3, based on gating strategies applied by others [23].

\section{TLR2-L SLP conjugate and cisplatin combined treatment in tumor-bearing mice}

Naïve C57BL/6 mice (Harlan Laboratories) of 6-8 weeks old were challenged with a TC-1 tumor as described above. Five nmole of the indicated constructs was injected subcutaneously in the tailbase in $50 \mu \mathrm{l}$ PBS on day 10, when the average tumor size was $12 \mathrm{~mm}^{3}$. Cisplatin was injected intraperitoneally in mice of indicated groups on day 10 and 17, at a suboptimal dose of $4 \mathrm{mg} / \mathrm{kg}$ as used previously in our group [18]. The tumor sizes were measured 2 or 3 times a week by use of a caliper. Mice were sacrificed when tumor sizes reached $2000 \mathrm{~mm}^{3}$, in accordance with Dutch animal welfare legislation.

\section{Combined TLR2-L SLP conjugate vaccination and PDT treatment in tumor-bearing mice}

Naïve C57BL/6 mice (Harlan Laboratories) of 6-8 weeks old were challenged with a TC-1 tumor as described above. For these experiments, 5 nmole of the indicated constructs was injected subcutaneously in the tailbase in $50 \mu \mathrm{l}$ PBS on day 6 according to optimized protocols in our lab. On day 6, tumors were palpable in all mice. On day 8 , photodynamic therapy (PDT) was performed on mice in indicated groups by intravenous injection of 20 $\mathrm{mg} / \mathrm{kg}$ Bremachlorin photosensitizer per mouse, followed $6 \mathrm{~h}$ later by local illumination of the tumor with a $662 \mathrm{~nm}$ laser at $116 \mathrm{~mW} / \mathrm{cm}^{2}$ for $1000 \mathrm{~s}$ (total light dose $116 \mathrm{~J} / \mathrm{cm}^{2}$ ), as described elsewhere [17]. The tumor sizes were measured 2 or 3 times a week by use of a caliper. Mice were sacrificed when tumor sizes reached $2000 \mathrm{~mm}^{3}$, in accordance with Dutch animal welfare legislation.

\section{Results}

The modified TLR2-L Amplivant improves conjugated SLP vaccination

Modification of TLR2-L Pam3CSK4 resulted in the generation of Amplivant (AV), a TLR2-L with enhanced DC activation potency [16]. In previous studies, we have shown that generation of specific T cell responses by SLP is markedly improved by conjugating the SLP to TLR2-L
Pam3CSK4 [12-14]. To test whether AV shares the ability to efficiently induce specific $\mathrm{T}$ cell responses, we conjugated both AV and Pam3CSK4 to an ovalbumin-derived SLP containing the $\mathrm{CD}^{+} \mathrm{T}$ cell epitope SIINFEKL $\left(\mathrm{SLP}_{\text {OVA CTL }}\right)$. DCs were loaded with titrating doses of either Pam3CSK4 or AV conjugated to SLP OVA CTL or with mixtures of free SLP and TLR2-L and subsequently co-cultured with SIINFEKL-specific $\mathrm{CD}^{+} \mathrm{T}$ cells derived from the transgenic OT1 mouse. At these low concentrations, both Pam3CSK4- and AV-SLPOVA CTL conjugates show a stronger induction of IFN $\gamma$ and TNF $\alpha$ production by OT1 T cells, as determined by intracellular cytokine staining, than a mixture of free TLR2-L and SLP OVA CTL (Fig. 1a, and b). Processing of the Pam3CSK4- and

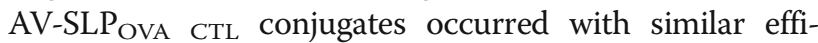
ciency as no difference in OT1 T cell activation was observed. In addition, we observe a total abrogation of $\mathrm{MHC}$ class I-dependent activation of a $\mathrm{T}$ cell hybridoma (B3Z) specific for the SIINFEKL CTL epitope (Additional file 1: Figure S1) using cells lacking transporter associated with antigen processing (TAP). This indicates that the processing and presentation of the epitope follows a classical cytosolic cross-presentation route after uptake.

Next, we vaccinated groups of naïve C57BL/6 mice subcutaneously (s.c.) with either the Pam3CSK4- or AV-SLP ${ }_{\text {OVA CTL }}$ conjugate. All mice received a booster vaccination 14 days later. Seven days after the boost, significantly more $\mathrm{K}^{\mathrm{b}}$-SIINFEKL tetramer-positive $\mathrm{CD}^{+} \mathrm{T}$ cells are detected in the vaccine-draining lymph nodes

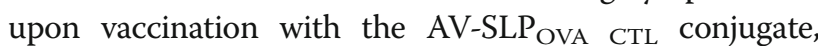
compared to Pam3CSK4-conjugate vaccinated mice (Fig. 1c). Also, significantly more specific $\mathrm{CD}^{+} \mathrm{T}$ cells are detected in the AV-SLP ${ }_{\text {OVA }} \mathrm{CTL}_{\text {-vaccinated }}$ group after ex vivo restimulation of the splenocytes (Fig. 1d). In line with our previous studies, conjugation of a TLR2-L to an SLP improves the induction of specific CD8 ${ }^{+}$ T cells as compared to a mixture of free SLP and TLR2-L [14]. As HPV16 is a clinically more relevant tumor antigen, we also conjugated AV and Pam3CSK4 to an SLP derived from HPV16 E7 which harbors a D ${ }^{\mathrm{b}}$-restricted MHC class I epitope [24]. After receiving three s.c. vaccinations, an enhanced average percentage of E7-specific $\mathrm{CD}^{+} \mathrm{T}$ cells is detected in blood and spleen in the mice vaccinated with AV-SLP $P_{\mathrm{HPV}}$, albeit not significantly (Additional file 1: Figure $\mathrm{S} 2 \mathrm{~A}$, and B). Notably, the mice in the AV-SLP $\mathrm{HPV}_{\mathrm{H}}$ conjugate group with the highest percentage of HPV16 E7-specific $\mathrm{CD}^{+} \mathrm{T}$ cells also had a higher percentage of antigen-specific effector/effector memory $\mathrm{T}$ cells, as indicated by the low expression of CD127 or CD62L and high expression of KLRG1 (Additional file 1: Figure S2C, and D).

\section{Amplivant induces potent murine DC activation}

In our previous study, we reported that AV induces enhanced murine DC maturation compared to Pam3CSK4 


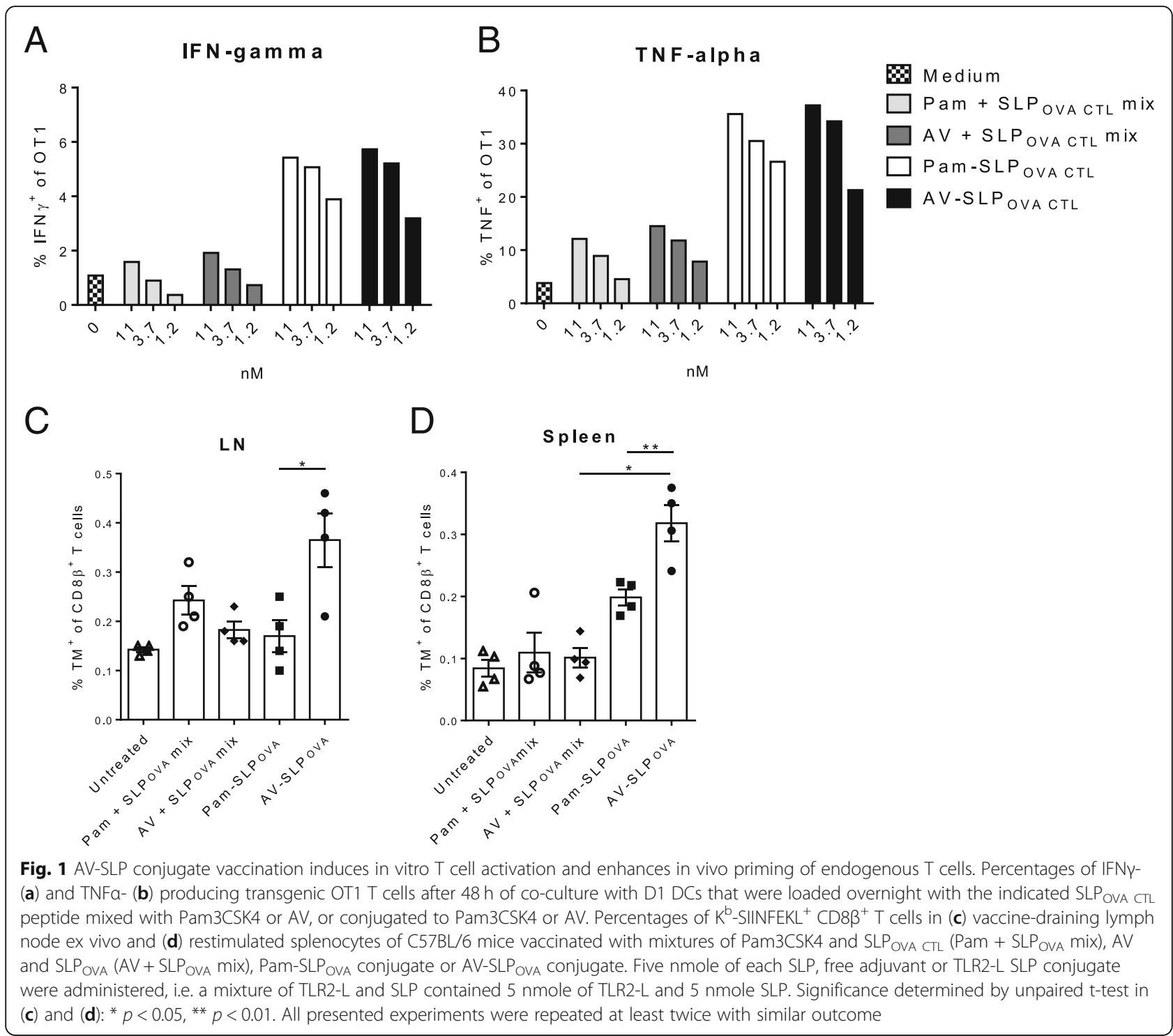

[16]. Looking more in-depth at the maturation potential of non-conjugated AV reveals enhanced IL-12p40 production and upregulation of MHC class II molecules (I-A ${ }^{\text {b }) ~ a n d ~ c o-s t i m u l a t o r y ~ m a r k e r s ~ C D 40 ~ a n d ~ C D 86 ~ b y ~}$ both a murine $\mathrm{DC}$ cell line and bone marrow-derived DCs (BMDC; Additional file 1: Figure S32) in comparison with non-conjugated Pam3CSK4. To determine whether AV also induces enhanced DC maturation upon conjugation to a an SLP which improved T cell priming, we stimulated murine BMDCs with titrating concentrations of either Pam3CSK4 or AV conjugated to three different SLPs: ovalbumin-derived SLP OVA CTL and SLP OVA $\mathrm{TH}$ and HPV16 E7-derived $\operatorname{SLP}_{\mathrm{HPV}}[14,25]$. Indeed, IL-12p40 production by BMDC upon stimulation with AV-conjugated SLP was significantly higher than Pam3CSK4-conjugated SLP (Fig. 2a, b and c). Although not always as pronounced as the IL-12p40 production, also the co-stimulatory marker CD86 was upregulated more strongly in response to stimulation with the AV-SLP conjugate (Fig. 2d, e and f) [24]. A representative dilution range is shown separately for each conjugated SLP as conjugation of AV to an SLP leads to different physicochemical properties for each SLP. Besides, the conditions of each cellular assay are slightly different. These data show that AV retains its effective DC activating capacity upon conjugation to SLPs, irrespective of SLP sequences.

\section{Favorable modulation of tumor-associated myeloid compartment upon vaccination of tumor-bearing mice with AV-SLP conjugate}

Next, we examined the effects of AV-SLP conjugate vaccination in mice carrying an established tumor. First, naïve C57BL/6 mice were challenged with TC-1 tumor 

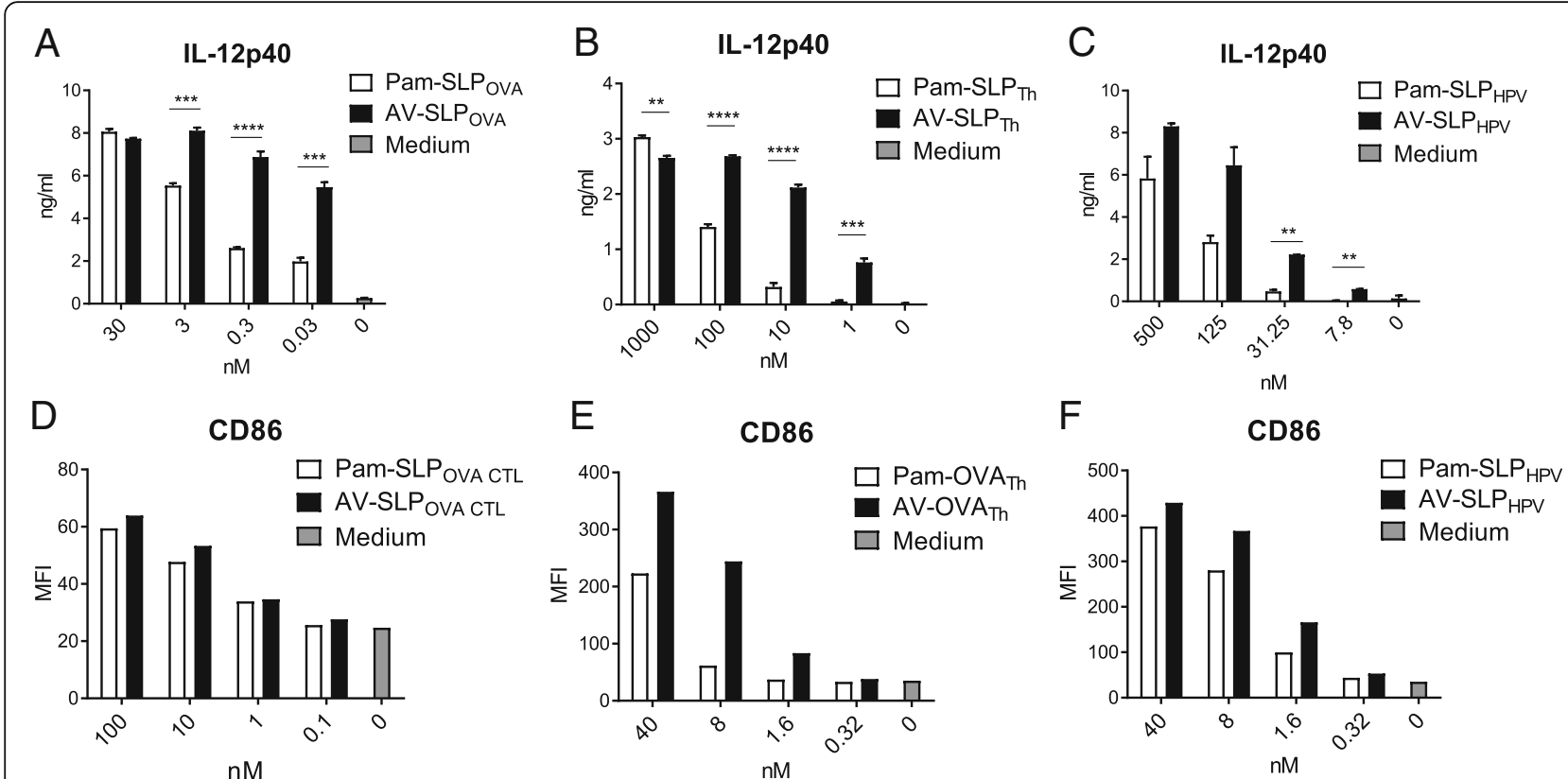

Fig. 2 AV retains its superior capacity in induction of DC maturation over Pam3CSK4 upon conjugation. (A - C) Concentration of IL-12p40 in the supernatant of BMDCs stimulated overnight with ovalbumin-derived SLP OVA CTL Or SLP OVA Th Or HPV16 E7-derived SLP HPV, conjugated to either Pam3CSK4 or AV. (D-F) Expression of CD86 (MFl; mean fluorescence intensity) on BMDCs stimulated overnight as in Fig. 2a, B and c. Results are representative of at least three independently performed experiments with each of the conjugated SLPs. Significance determined by unpaired t-test: ${ }^{*} p<0.05,{ }^{* *} p<0.01,{ }^{* * *} p<0.001,{ }^{* * *} p<0.0001$

cells which express the HPV16 oncoproteins E6 and E7 [19]. After 10 days, when average tumor sizes reached $12 \mathrm{~mm}^{3}$, mice were s.c. vaccinated with either AV-SLP ${ }_{\text {HPV }}$ or vehicle only. Nine days after the vaccination, when the expected peak of the $\mathrm{T}$ cell response and tipping point in the tumor regression phase coincide, all mice were sacrificed and the phenotypes of the infiltrating lymphocyte and myeloid populations were analyzed. No significant differences were seen in tumor size at this time point (data not shown). Vaccination with the conjugates led to a strong infiltration of $\mathrm{CD}^{+} \mathrm{T}$ cells into the tumor while the percentages of $\mathrm{CD}^{+} \mathrm{T}$ cells in the tumor were similar to those in untreated mice (Fig. 3a). Of these $\mathrm{CD}^{+}{ }^{+} \mathrm{T}$ cells, an average of approximately $10 \%$ was specific for the CTL epitope (RAHYNIVTF) embedded in the conjugated vaccine SLP. In a recent study, four tumor-infiltrating myeloid populations were identified based on the expression of CD11b, F4/80 and Ly6C (Additional file 1: Figure S4.A) [23]. Of these, the frequency of inflammatory macrophages $\left(\mathrm{CD}^{-} \mathrm{CD} 11 \mathrm{~b}^{+} \mathrm{Ly} 6-\right.$ $\mathrm{C}^{\text {hi }} \mathrm{F} 4 / 80^{\mathrm{hi}}$ ) after peptide vaccination correlated with the infiltration of $\mathrm{CD}^{+} \mathrm{T}$ cells. In the present study, we observe a highly significant increase in the frequency of intratumoral inflammatory macrophages upon vaccination with $\mathrm{AV}-\mathrm{SLP}_{\mathrm{HPV}}$. At the same time, vaccination also led to decreased levels of tissue-resident macrophages

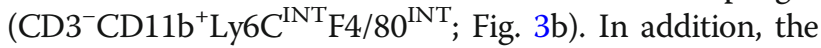
AV-SLP ${ }_{\mathrm{HPV}}$ conjugate induces stronger upregulation of the DC marker CD11c on all gated myeloid populations except for the granulocytic myeloid cells, which may reflect differentiation towards a more DC-like phenotype. A direct comparison between AV-SLP $\mathrm{HPV}_{\mathrm{H}}$ and Pam-SLP $\mathrm{HPV}$ conjugate vaccination revealed that both conjugates are highly similar in their potency to induce tumor infiltration by $\mathrm{T}$ cells and modulation of the intratumoral myeloid populations (Additional file 1: Figure S4.B, C and D). Overall, these results provide important insights into the effects of TLR2-L SLP conjugate vaccination in TC-1 tumor-bearing mice, showing the favorable skewing effect towards the inflammatory macrophage phenotype by AV-SLP $\mathrm{HPV}_{\mathrm{HP}}$ conjugate vaccination.

\section{AV-SLP conjugate vaccination improves therapeutic antitumor response}

In previous studies, we found that conjugates of Pam3CSK4 and SLP were superior to mixtures of Pam3CSK4 and SLP in prophylactic tumor models. In the present study, we s.c. vaccinated mice carrying an established TC-1 tumor with AV-SLP ${ }_{\mathrm{HPV}}$ or a mixture of AV and $\mathrm{SLP}_{\mathrm{HPV}}$ and found that conjugation of AV to SLP $\mathrm{HPV}_{\mathrm{HPV}}$ significantly enhanced the survival of TC-1-bearing mice in a therapeutic setting (vaccination on day 8 after tumor challenge; Fig. 4a). To study whether the favorable effects in the tumor microenvironment induced by AV-SLP $\mathrm{HPV}_{\mathrm{H}}$ conjugate vaccination led to efficient tumor eradication, C57BL/6 mice carrying a palpable TC-1 tumor were 


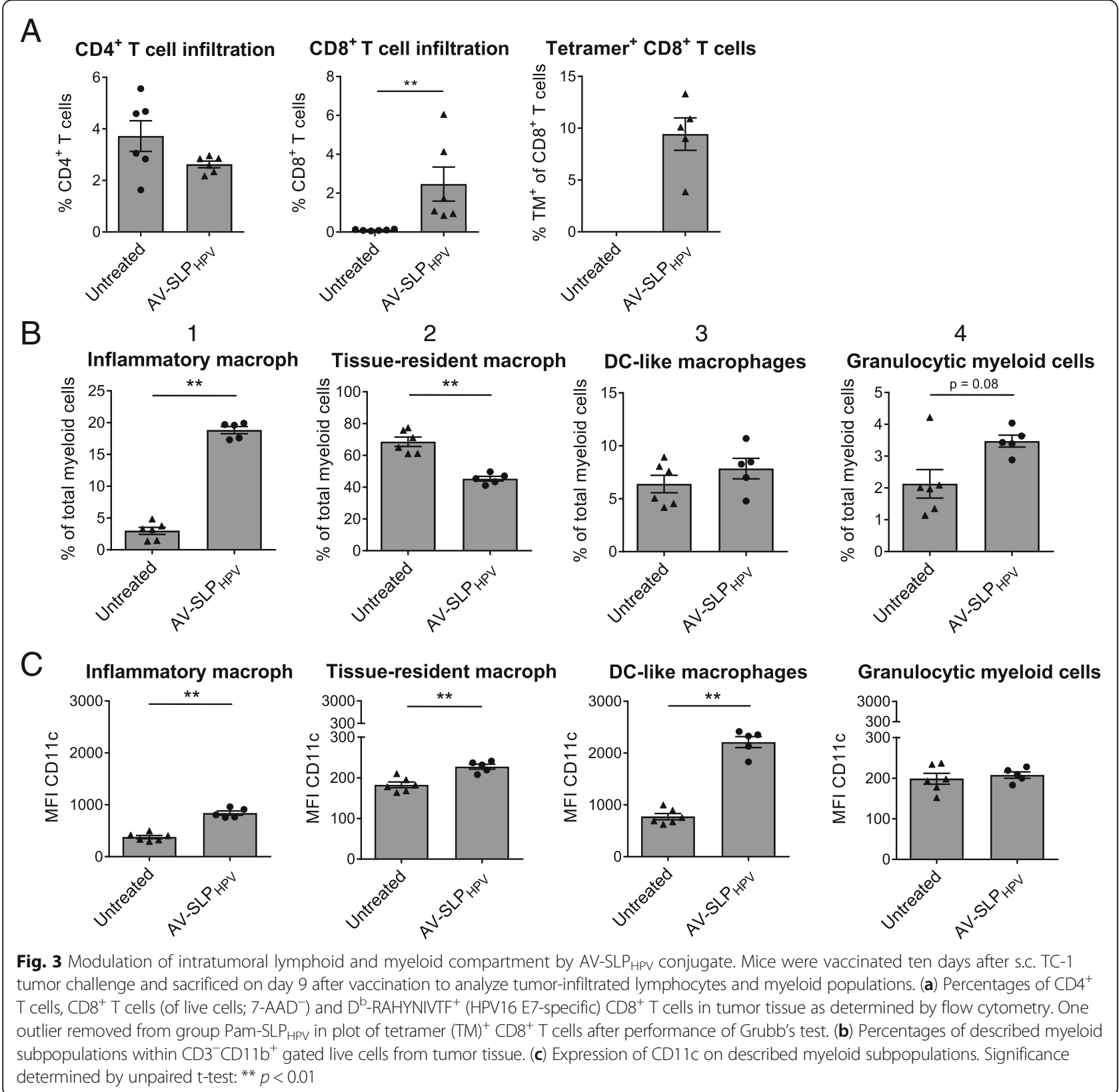

vaccinated with either AV-SLP $P_{\mathrm{HPV}}$ or Pam-SLP $\mathrm{HPV}_{\mathrm{HP}} \mathrm{Tu}$ mors of mice vaccinated with AV-SLP $\mathrm{HPV}_{\mathrm{HP}}$ on day 8 after tumor challenge remained significantly smaller during the initial tumor growth phase than those of mice vaccinated with Pam-SLP $\mathrm{HPV}_{\mathrm{H}}$ (Additional file 1: Figure S5A) which was also reflected in improved early phase survival between day 20 and 40 (Additional file 1: Figure S5B). A stronger and more significant reduction in tumor size was observed when mice were vaccinated with AV-SLP $\mathrm{HPV}_{\mathrm{HPV}}$ conjugate on day 10 after tumor challenge, when mice have developed larger tumor sizes (approximately 12 $\mathrm{mm}^{3}$ ) at the moment of vaccination (Fig. 4b). Interestingly, the time point at which tumors start to regress in the AV-SLP conjugate-vaccinated group is earlier than in the Pam-SLP conjugate-vaccinated group. Moreover, AV-SLP ${ }_{\text {HPV }}$ conjugate vaccination resulted in a significant survival benefit compared with Pam-SLP $\mathrm{HPV}_{\text {-vaccinated }}$ mice (Fig. 4c).

\section{Combinations of ablative therapy and AV-SLP vaccination} synergize in tumor eradication

The observation that only approximately $10-20 \%$ of TC-1 tumor-bearing mice are cured by therapeutic vaccination (Fig. 4a, c) shows that AV-SLP conjugate vaccination on its own is not capable to mediate tumor eradication in the majority of animals in this model. In a 


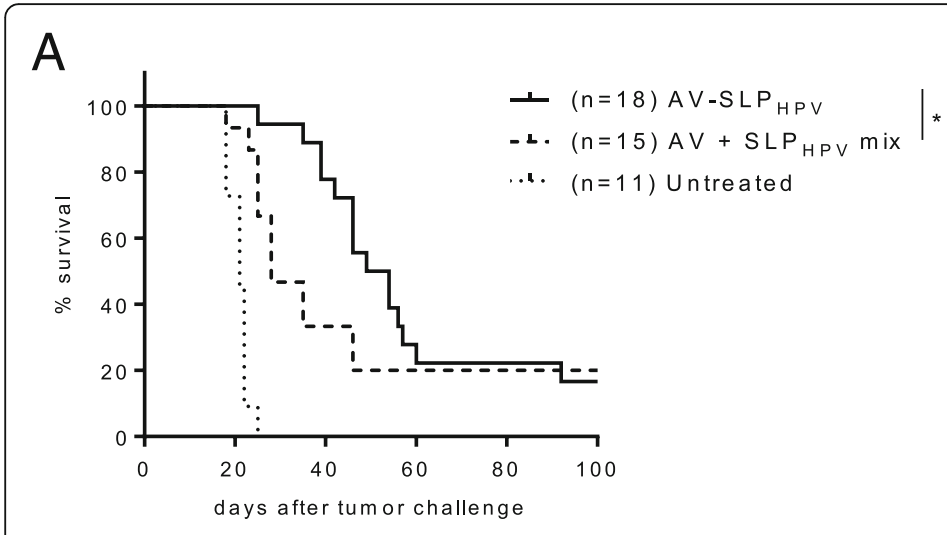

B

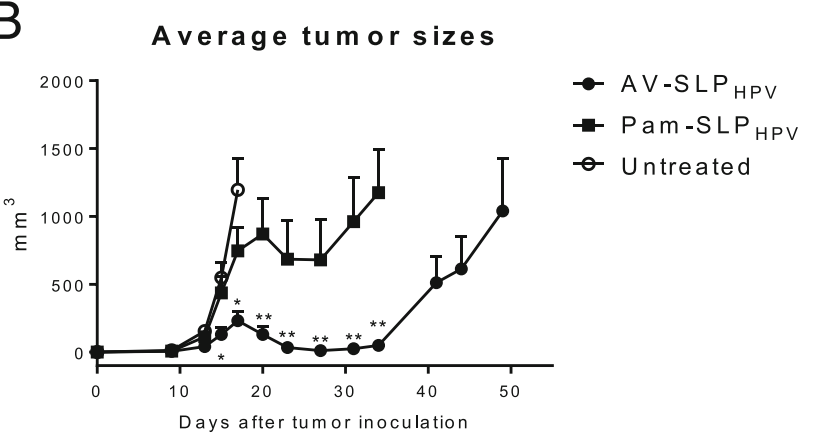

C

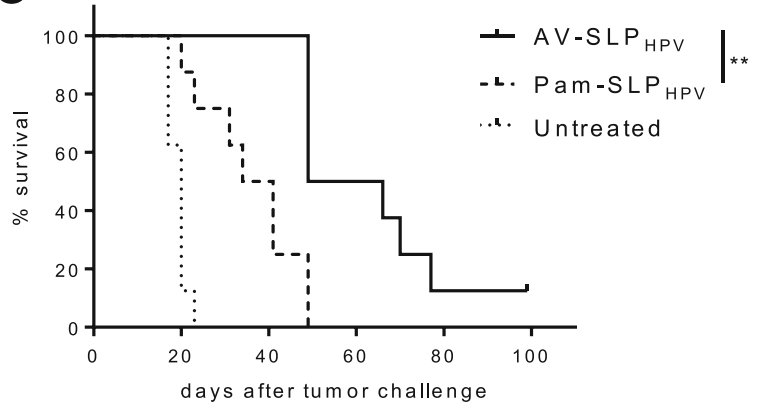

Fig. 4 TC-1 tumors initially grow slower in mice vaccinated with AV-SLP ${ }_{H P V}$ conjugate. (a) Kaplan-Meier survival plot of C57BL/6 mice carrying a TC-1 tumor vaccinated with indicated vaccines. Data pooled from two identically performed experiments, total number of mice per group indicated as n. Significant difference between AV + SLP HPV mix and AV-SLP HPV ( $\left.{ }^{*} p=0.014\right)$ determined by Gehan-Breslow Wilcoxon test. (b) Average tumor size per group of mice vaccinated with either AV-SLPHPV or Pam-SLP HPV conjugates, or not vaccinated (Untreated). Average tumor size followed in time until first mouse was sacrificed due to tumor burden. Significance determined by Mann Whitney t-test $\left({ }^{*} p<0.05\right.$; $\left.{ }^{*} p<0.01\right)$. (c) Kaplan-Meier plot showing survival of mice vaccinated in same experiment as (b). Significance determined by log-rank test $\left.{ }^{* *} p<0.01\right)$

clinical setting, patients usually receive standard-of-care chemotherapy and/or radiotherapy to treat HPV16-induced cancer. SLP vaccination has recently been shown to synergize with a suboptimal dose of cisplatin in the eradication of TC-1 tumors in mice, partially explained by the enhanced apoptosis of tumor cells by TNF $\alpha$ from SLP-induced $T$ cells in the presence of cisplatin [18]. Therefore, we tested whether synergistic tumor eradication could also be achieved upon combined cisplatin and $\mathrm{AV}_{-} \mathrm{SLP}_{\mathrm{HPV}}$ treatment in TC-1-bearing mice. Mice were vaccinated s.c. with $\mathrm{AV}-\mathrm{SLP}_{\mathrm{HPV}}$ on day 10 after tumor challenge, while cisplatin was injected intraperitoneally at a dose of $4 \mathrm{mg} / \mathrm{kg}$ cisplatin, well below the maximum tolerated dose. The treatment timeline is depicted in Fig. 5a. Both cisplatin treatment and $\mathrm{AV}-\mathrm{SLP}_{\mathrm{HPV}}$ vaccination alone delayed the outgrowth of most tumors but were not curative for the majority of mice (Fig. 5b). The combination treatment resulted in a significantly better survival (71\% versus $12.5 \%$ ) compared to the group vaccinated with AV-SLP ${ }_{\mathrm{HPV}}$ only.

Another immunomodulatory therapy, photodynamic therapy (PDT), acts by laser-induced local cytotoxicity after administration of the photosensitizer Bremachlorin which accumulates selectively in tumor tissue [17]. We combined PDT with s.c. AV-SLP ${ }_{\mathrm{HPV}}$ vaccination to examine whether these treatments act synergistically. PDT treatment or $\mathrm{AV}-\mathrm{SLP} \mathrm{HPV}_{\mathrm{HPV}}$ vaccination on itself delayed tumor outgrowth in the TC- 1 model (1 mouse out of 8 cured in both groups; $12.5 \%$; Fig. $5 \mathrm{c}$ ), while the combin-

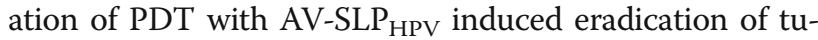
mors in 8 out of 9 mice (89\%; Fig. 5c). Out of the 8 cured mice, 7 developed a strong memory response as these mice were protected from a rechallenge with TC-1 tumor cells in the opposite flank. Both surviving mice of the AV-SLP ${ }_{\mathrm{HPV}}$ and PDT monotherapy groups were protected as well from the rechallenge (Fig. 5c). These data show that AV-SLP conjugate vaccines can be effectively combined with chemotherapy or photodynamic therapy.

\section{Discussion}

We consistently observe enhanced maturation of murine DCs by AV either as a free ligand or conjugated to any peptide sequence tested so far. Interestingly, the physical and chemical properties of each conjugate may differ, as observed before [26]. While the Pam- and AV-SLP CTL conjugates still retain strong activation potency in 
A
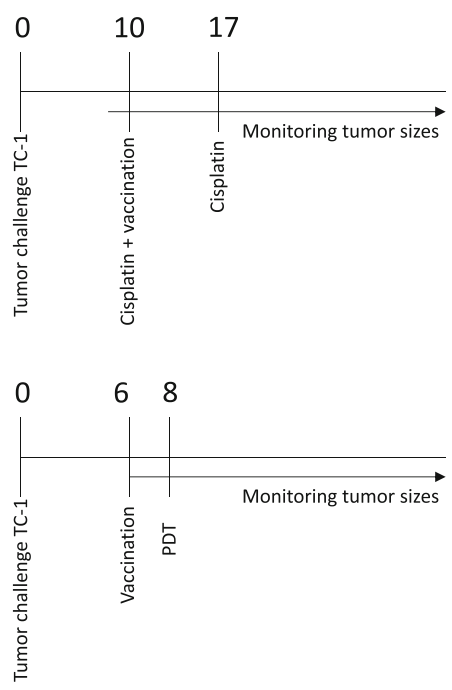

B
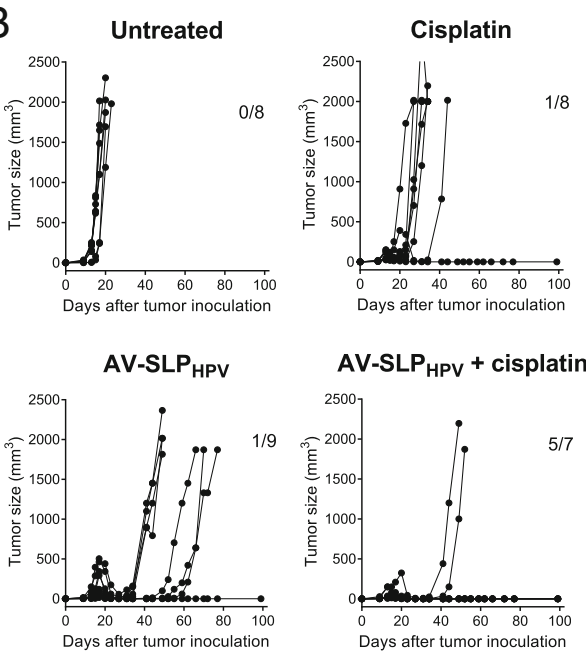

AV-SLP $\mathrm{HPV}_{\text {+ cisplatin }}$

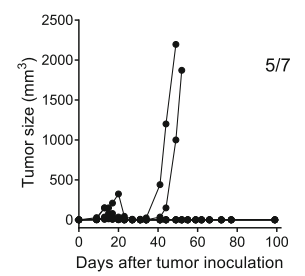

C
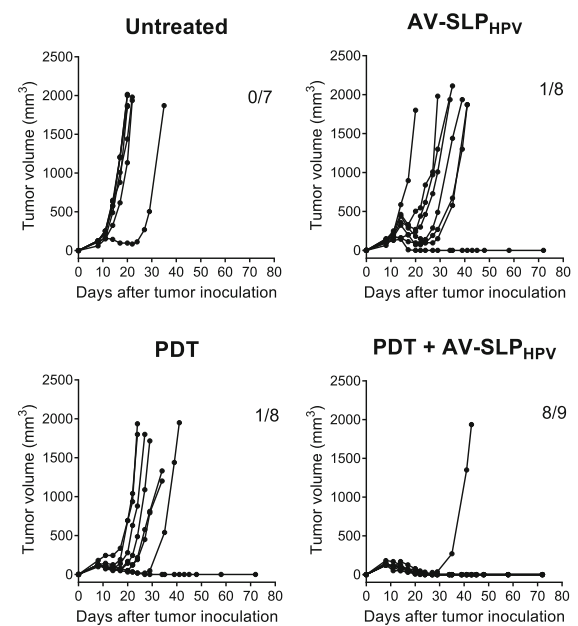

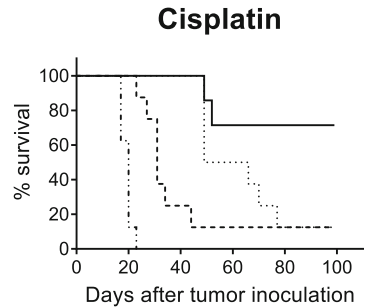

- AV-SLP $\mathrm{HPV}_{\mathrm{H}}+\mathrm{Cis}$ AV-SLP
Cisplatin ... Untreated

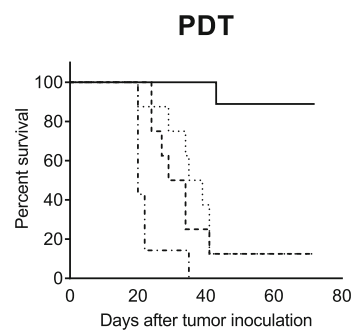

$\begin{aligned} & \text { - PDT + AV-SLP } \\ & \ldots \text { APV } \\ & \ldots \text { AVLPHPV }\end{aligned} \mid$

-.. PDT

-.- Untreated

Fig. 5 (See legend on next page.) 
(See figure on previous page.)

Fig. 5 Combination of AV-SLP HPV conjugate vaccination and immunomodulatory therapy in TC-1 tumor model. (A) Overview of experimental setup (timelines). Numbers indicate number of days after tumor challenge. (B) Tumor growth curves and Kaplan-Meier survival plot of combination treatment of AV-SLP HPV conjugate vaccination and i.p. cisplatin treatment. Numbers in graph indicate number of cured mice of total in group. Results are shown of one of two experiments with similar outcome. (C) Combination treatment of AV-SLP HPV conjugate vaccination and photodynamic therapy (PDT). Tumor growth curves and Kaplan-Meier survival plots of groups of mice carrying a TC-1 tumor vaccinated with indicated vaccines. Bottom KaplanMeier plot represents survival of mice after re-challenge with TC-1 tumor cells at day 55. Significance determined by log-rank test; ${ }^{*} p<0.05 ;{ }^{* *} p<0.01$; ${ }^{* * *} p<0.001$

terms of IL-12p40 induction in the picomolar range, the Pam-SLP ${ }_{\mathrm{OVA}} \mathrm{Th}^{-}$and Pam-SLP $\mathrm{HPV}$-conjugates lose their activity in the low nanomolar range. As the peptide part of each conjugate greatly differs in amino acid composition, also the solubility and binding stability may vary depending on the amount of hydrophilic and hydrophobic residues.

After binding of Pam3CSK4 and AV to TLR2 on the cell surface of DCs and the subsequent maturation process, the constructs are ingested and processed by the DCs resulting in the generation of the exact MHC ligands [12]. Using transgenic OT1 cells as a T cell read-out, we found that both Pam- and AV-conjugated SLPs are efficiently taken up and processed but do not differ in their capacity to induce $\mathrm{T}$ cell activation. This may be explained by the fact that the DC activation and concomitant cytokine expression and upregulation of co-stimulatory markers reach a saturating level for activation of the low-threshold OT1 transgenic T cells. Both conjugates outperformed a mixture of SLP and either AV or Pam3CSK4. We have reported the superiority of conjugates over mixtures of TLR2-L and SLP before [12], which can be explained by an enhanced uptake of the TLR2-L SLP OVA CTL conjugates through DC targeting by their lipophilic properties.

In contrast to these in vitro data, a significant difference was found in potency of the two conjugated ligands with respect to $\mathrm{T}$ cell priming in vivo, as the AV-SLP OVA conjugates were shown to more effectively expand $T$ cells of the murine endogenous $\mathrm{T}$ cell repertoire. Comparing $\mathrm{AV}^{-S L P} \mathrm{P}_{\mathrm{HPV}}$ and Pam-SLP $\mathrm{HPV}_{\mathrm{HP}}$ conjugate-induced specific $\mathrm{T}$ cells, differences in $\mathrm{T}$ cell activation markers were less pronounced. However, differential potency in T cell activation by AV and Pam3CSK4 was suggested by skewing of the $\mathrm{T}$ cell response towards a more effector (memory) $\mathrm{T}$ cell-like phenotype which was observed in part of the mice vaccinated with the AV-SLP $\mathrm{HPV}_{\mathrm{HP}}$ conjugate. Based on their general molecular structure Pam3CSK4 and AV share similar in vivo targeting potential. Therefore, the enhanced priming of $\mathrm{CD}^{+} \mathrm{T}$ cells is most likely explained by the stronger binding of AV to TLR2-expressing APCs. In a previous study, we have assessed the influence of DC maturation on $\mathrm{T}$ cell priming by conjugating either the functional R-Pam3CSK4 or dysfunctional S-Pam3CSK4 stereoisomer to an SLP [13]. Although S-Pam-SLP conjugates could induce $\mathrm{T}$ cell priming in vivo, the $R$-Pam-SLP performed significantly better. Therefore, it is likely that the enhanced activation of DCs by AV positively affects the strength of $\mathrm{T}$ cell responses.

Given the results discussed above, we analyzed whether AV-SLP conjugates were also more effective as therapeutic vaccines in an established HPV-tumor model. As the data in Fig. $4 \mathrm{~b}$ and $\mathrm{c}$ demonstrate, AV-SLP $\mathrm{HPV}_{\text {vaccination has }}$ superior antitumor efficacy over Pam-SLP $\mathrm{HPV}_{\mathrm{H}}$ vaccination. In this setting, mice had large established tumors, indicating the strength of AV-SLP $\mathrm{HPV}^{-i n d u c e d ~ a n t i t u m o r ~ i m-~}$ mune responses. Mice carrying a tumor that was just palpable (day 8 after tumor challenge) also benefited stronger from AV-SLP $\mathrm{HPV}_{\text {than }}$ Pam-SLP $\mathrm{HPV}_{\mathrm{HPV}}$ vaccination, although differences were smaller (Additional file 1: Figure S5) suggesting that antigenic load may affect therapeutic vaccination potency. These data show that the enhanced TLR potency of AV is also beneficial for therapeutic antitumor efficacy.

The mechanism behind the decreased tumor growth in

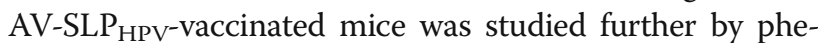
notyping the tumor-infiltrating lymphocytes and myeloid cells. The myeloid infiltrate can be highly heterogeneous within tumors but much can be learned from studies focusing on the roles of specific myeloid subtypes in immunization and infection settings [27]. Ly6 $\mathrm{C}^{\mathrm{hi}}$ monocytes are described to be precursors of tumor-associated macrophages and inflammatory DCs. The latter are capable of efficient antigen presentation and retain $\mathrm{Ly} 6 \mathrm{C}^{\mathrm{hi}}$ expression after differentiation. The Ly6C ${ }^{\text {hi }}$ DCs play an important role in the onset of $\mathrm{T}_{\mathrm{H}} 1 \mathrm{~T}$ cell responses and may therefore be considered reminiscent of M1 myeloid cells [28]. The inflammatory macrophages detected in this study also expressed intermediate levels of CD11c (Fig. 3d), the expression of which was strongly upregulated by AV-SLP ${ }_{\mathrm{HPV}}$, but it remains to be determined whether these cells share the same fate and properties with the inflammatory DCs.

The expression of TLR2 is very low or absent on T cells but abundant on several myeloid cells [29], which suggests

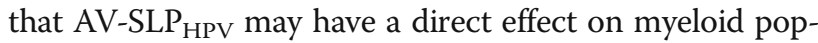
ulations in the tumor area besides the induction of specific $\mathrm{T}$ cells via APCs in lymphoid organs. Unfortunately, not much is known about TLR2 expression on these cell 
populations. Both $\mathrm{AV}$ - and Pam-SLP $\mathrm{HPV}_{\mathrm{HP}}$ conjugates reduced the frequency of tissue-resident macrophages. Although likely, we cannot conclude whether tissue-resident macrophages have been modulated towards an inflammatory macrophage phenotype. Another theoretical explanation for the observed skewing may be found in the induction of tumor cell death. Ma et al report on the attraction of myeloid cells into the tumor by ATP released from dying cancer cells [30]. These cells could further dif-

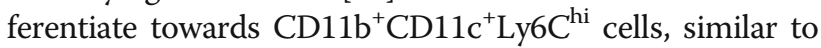
the inflammatory macrophage population we find in tumors in the current study. Therefore, by directly inducing tumor cell death, AV may indirectly attract and cause differentiation of myeloid populations in the tumor microenvironment. Another attractive explanation is that the tumor microenvironment is influenced by the induced $\mathrm{T}$ cell response. As we have shown that AV conjugated to HPV16 E6-derived SLPs can stimulate Th1-type T cells in tumor draining LN cells derived from cervical cancer patients [26], it is conceivable that this type of T cells can indirectly skew the tumor environment to a more favorable myeloid cell composition [23].

Figure 4 shows that AV-SLP $\mathrm{HPV}_{\mathrm{HP}}$ vaccination alone does not suffice to permanently eradicate most TC- 1 tumors. However, we saw highly potent effects of AV-SLP vaccination in combination treatment with cisplatin and photodynamic therapy (PDT), mediating cures in the large majority of mice where either treatment alone was only effective in a small minority of animals (Fig. 5b, c). This synergistic effect may be explained by several simultaneously operating mechanisms: 1) induction of immunogenic cell death by cisplatin, leading to release of several immunomodulators from dying tumor cells [31]; 2) secretion of TNF $\alpha$ by the SLP vaccine-induced T cells in the tumor microenvironment and increased sensitivity of tumor cells to TNF $\alpha$-mediated apoptosis in the presence of cisplatin $[18], 3)$ selective depletion of immunosuppressive immature myeloid cells by chemotherapy as was shown for carboplatin and paclitaxel [32]. As the AV-SLP $\mathrm{HPV}_{\mathrm{HPV}}$ conjugate even more adequately induces $\mathrm{T}$ cell responses than SLPs alone, it is likely that the same mechanisms apply here.

Our group recently reported on the synergistic effects of a combination of PDT and immunotherapy [17]. Also, the combination of PDT with AV-SLP ${ }_{\mathrm{HPV}}$ vaccination resulted in strongly improved established tumor eradication. The mechanisms underlying the synergism observed by combination of PDT and AV-SLP $\mathrm{HPV}_{\text {C }}$ conjugate vaccination are likely explained by induction of immunogenic cell death [17]. Elevated cross-presentation and T cell activation in combination with our optimized conjugate vaccine resulted in effective synergy in immune control of tumors and cure of almost all animals.

Overall, we conclude that the modification of Pam3CSK4 as applied in the TLR2-L Amplivant ${ }^{\mathrm{Tm}}$ results in enhanced immunological effects which are beneficial in cancer immunotherapy in mice, particularly when used in synthetic long peptide-conjugate vaccines. These promising results pave the way for further clinical testing of AV-SLP conjugates. Currently, a phase I/II clinical trial has started to assess the dosing and safety profile of two HPV16 E6-derived SLPs conjugated to AV.

\section{Conclusions}

The present study provides insight in the enhanced immunological effects of the novel TLR2-L Amplivant ${ }^{\text {tw }}$ (AV) in comparison with the reference compound Pam3CSK4. We show that the enhanced activation of DCs in vitro also translates to enhanced endogenous $\mathrm{T}$ cell priming in vivo when $\mathrm{AV}$ is conjugated to SLP. For the first time, we show that AV-SLP conjugates applied in an established tumor setting induced therapeutic antitumor efficacy, which was stronger than Pam-SLP ${ }_{\mathrm{HPV}}$ conjugate vaccination. The synergy between SLP-conjugated AV and each of two different standard anti-cancer therapies shows the strong therapeutic potential of this TLR2-L.

\section{Additional file}

\begin{tabular}{|c|}
\hline 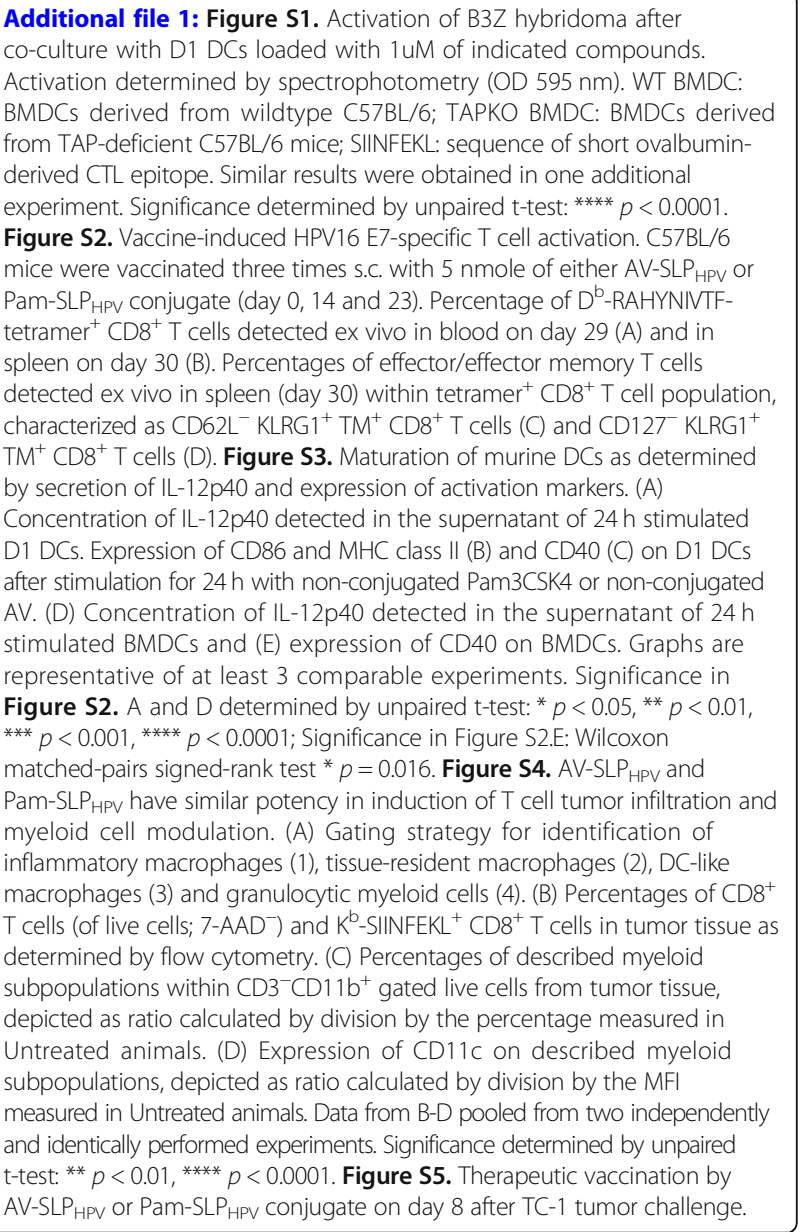 \\
\hline
\end{tabular}


Data pooled from 5 identically performed experiments; 47 mice per group. (A) Tumor volumes $\left(\mathrm{mm}^{3}\right)$ measured in TC-1 tumor-carrying C57BL/6 mice after vaccination with AV-SLP $P_{H P V}$ or Pam-SLP $P_{H P V}$ conjugate. X-axis indicates days after vaccination; days of measurements in the different experiments were distributed over 2-day intervals to enable combining of data. Non-parametric Wilcoxon test revealed significant difference $\left({ }^{*} p=0.016\right)$ between vaccinated groups. (B) Kaplan-Meier survival plot of C57BL/6 mice carrying a TC-1 tumor vaccinated with AV-SLP $\mathrm{HPV}_{\text {or Pam-SLP }}$ HPV Conjugate. (PDF $189 \mathrm{~kb})$

\section{Abbreviations}

APC: Antigen presenting cell; AV: Amplivant; CD: Cluster of differentiation; DC: Dendritic cell; ELISA: Enzyme-linked immunosorbent assay; HPV: Human Papilloma Virus; IFN: Interferon; Pam3CSK4: N-palmitoyl-S-(2, 3-bis (palmitoyl)(2RS)-propyl)-(R)-Cys-Ser-Lys-Lys-Lys-Lys; PAMP: Pathogen-associated molecular pattern; PDT: Photodynamic therapy; SLP: Synthetic long peptide; TLR: Toll-like receptor; TNF: Tumor necrosis factor

\section{Acknowlegdements}

Not applicable to this study.

\section{Funding}

This work has been funded by a Dutch Cancer Society (KWF) grant (UL2007-3906).

\section{Availability of data and materials}

The datasets used and/or analysed during the current study are available from the corresponding author on reasonable request.

\section{Synopsis}

Therapeutic cancer vaccination strategies are emerging as novel treatment options for cancer patients. In the present study, we study the efficacy of peptide-based vaccines in which a strong immune stimulus (a novel TLR2-ligand) is incorporated in murine tumor models.

\section{Authors' contributions}

GZ made substantial contributions to conception and design, acquired data and analysed and interpreted data. MW made substantial contributions to conception and design and synthetically generated the studied materials. SK made substantial contributions to conception and design. TS, JWK and MC acquired data and have been involved in critically revising the manuscript. GM, CM made substantial contributions to conception and design and interpretation of data, and critically revised the manuscript. DF made substantial contributions to conception and design of the study, as well as innovation of the studied synthetic materials, and critically revised the manuscript. FO made substantial contributions to conception and design, interpretation of data, drafting of the manuscript and general supervision of the study. All authors read and approved the final manuscript.

\section{Ethics approval and consent to participate}

Not applicable to this study.

\section{Consent for publication}

Not applicable to this study.

\section{Competing interests}

CJM Melief is chief scientific officer of biotech company ISA (Immune System Activation), aiming at development of synthetic peptide -based cancer vaccines, including conjugates between a proprietary TLR ligand and synthetic long peptides. As CSO, CJM Melief receives a salary from ISA and is in possession of stock appreciation rights. In addition, CJM Melief is inventor on numerous patents that are licensed to or owned by ISA dealing with synthetic long peptide vaccines or dealing with the proprietary TLR ligand used in this paper.

\section{Publisher's Note}

Springer Nature remains neutral with regard to jurisdictional claims in published maps and institutional affiliations.

\section{Author details}

'Department of Immunohematology and Blood Transfusion, section Tumorimmunology, Leiden University Medical Center, Leiden, The Netherlands. 'Leiden Institute of Chemistry, Leiden University, Leiden, The Netherlands. ${ }^{3}$ ISA Pharmaceuticals BV, Leiden, The Netherlands.

Received: 23 February 2018 Accepted: 16 November 2018

Published online: 12 December 2018

\section{References}

1. Kawai T, Akira S. The role of pattern-recognition receptors in innate immunity: update on toll-like receptors. Nat Immunol. 2010;11(5):373-84.

2. Casella CR, Mitchell TC. Putting endotoxin to work for us: monophosphoryl lipid a as a safe and effective vaccine adjuvant. Cell Mol Life Sci. 2008;65(20): 3231-40.

3. Domingos-Pereira S, Decrausaz L, Derre L, Bobst M, Romero P, Schiller JT, Jichlinski P, Nardelli-Haefliger D. Intravaginal TLR agonists increase local vaccine-specific CD8 T cells and human papillomavirus-associated genitaltumor regression in mice. Mucosal Immunol. 2013;6(2):393-404.

4. Goff PH, Hayashi T, Martinez-Gil L, Corr M, Crain B, Yao S, Cottam HB, Chan M, Ramos I, Eggink D, et al. Synthetic toll-like receptor 4 (TLR4) and TLR7 ligands as influenza virus vaccine adjuvants induce rapid, sustained, and broadly protective responses. J Virol. 2015;89(6):3221-35.

5. Huleatt JW, Nakaar V, Desai P, Huang Y, Hewitt D, Jacobs A, Tang J, McDonald W, Song L, Evans RK, et al. Potent immunogenicity and efficacy of a universal influenza vaccine candidate comprising a recombinant fusion protein linking influenza M2e to the TLR5 ligand flagellin. Vaccine. 2008;26(2):201-14.

6. Perret R, Sierro SR, Botelho NK, Corgnac S, Donda A, Romero P. Adjuvants that improve the ratio of antigen-specific effector to regulatory $T$ cells enhance tumor immunity. Cancer Res. 2013;73(22):6597-608.

7. Prajeeth CK, Jirmo AC, Krishnaswamy JK, Ebensen T, Guzman CA, Weiss S, Constabel H, Schmidt RE, Behrens GM. The synthetic TLR2 agonist BPPcysMPEG leads to efficient cross-priming against co-administered and linked antigens. Eur J Immunol. 2010;40(5):1272-83.

8. Sogaard OS, Lohse N, Harboe ZB, Offersen R, Bukh AR, Davis HL, Schonheyder $\mathrm{HC}$, Ostergaard L. Improving the immunogenicity of pneumococcal conjugate vaccine in HIV-infected adults with a toll-like receptor 9 agonist adjuvant: a randomized, controlled trial. Clin Infect Dis. 2010;51(1):42-50.

9. Oosting $\mathrm{M}$, Cheng SC, Bolscher JM, Vestering-Stenger R, Plantinga TS, Verschueren IC, Arts P, Garritsen A, van Eenennaam H, Sturm P, et al. Human TLR10 is an anti-inflammatory pattern-recognition receptor. Proc Natl Acad Sci U S A. 2014;111(42):E4478-84.

10. Reitermann A, Metzger J, Wiesmuller KH, Jung G, Bessler WG. Lipopeptide derivatives of bacterial lipoprotein constitute potent immune adjuvants combined with or covalently coupled to antigen or hapten. Biol Chem Hoppe Seyler. 1989;370(4):343-52.

11. Spohn R, Buwitt-Beckmann U, Brock R, Jung G, Ulmer AJ, Wiesmuller KH. Synthetic lipopeptide adjuvants and toll-like receptor 2--structure-activity relationships. Vaccine. 2004;22(19):2494-9.

12. Khan S, Bijker MS, Weterings JJ, Tanke HJ, Adema GJ, van Hall T, Drijfhout JW, Melief CJ, Overkleeft HS, van der Marel GA, et al. Distinct uptake mechanisms but similar intracellular processing of two different toll-like receptor ligand-peptide conjugates in dendritic cells. J Biol Chem. 2007; 282(29):21145-59

13. Khan S, Weterings JJ, Britten CM, de Jong AR, Graafland D, Melief CJ, van der Burg SH, van der Marel G, Overkleeft HS, Filippov DV, et al. Chirality of TLR-2 ligand Pam3CysSK4 in fully synthetic peptide conjugates critically influences the induction of specific CD8+ T-cells. Mol Immunol. 2009;46(6):1084-91.

14. Zom GG, Khan S, Britten CM, Sommandas V, Camps MG, Loof NM, Budden CF, Meeuwenoord NJ, Filippov DV, van der Marel GA, et al. Efficient induction of antitumor immunity by synthetic toll-like receptor ligandpeptide conjugates. Cancer Immunol Res. 2014;2(8):756-64.

15. Jin MS, Kim SE, Heo JY, Lee ME, Kim HM, Paik SG, Lee H, Lee JO. Crystal structure of the TLR1-TLR2 heterodimer induced by binding of a tri-acylated lipopeptide. Cell. 2007;130(6):1071-82.

16. Willems MM, Zom GG, Khan S, Meeuwenoord N, Melief CJ, van der Stelt M, Overkleeft HS, Codee JD, van der Marel GA, Ossendorp F, et al. Ntetradecylcarbamyl lipopeptides as novel agonists for toll-like receptor 2. J Med Chem. 2014;57(15):6873-8.

17. Kleinovink JW, van Driel PB, Snoeks TJ, Prokopi N, Fransen MF, Cruz L, Mezzanotte L, Chan A, Lowik CW, Ossendorp F. Combination of 
photodynamic therapy and specific immunotherapy efficiently eradicates established tumors. Clin Cancer Res. 2016;22(6):1459-68.

18. van der Sluis TC, van Duikeren S, Huppelschoten S, Jordanova ES, Beyranvand Nejad E, Sloots A, Boon L, Smit VT, Welters MJ, Ossendorp F, et al. Vaccineinduced tumor necrosis factor-producing T cells synergize with cisplatin to promote tumor cell death. Clin Cancer Res. 2015;21(4):781-94.

19. Lin KY, Guarnieri FG, Staveley-O'Carroll KF, Levitsky HI, August JT, Pardoll DM, Wu TC. Treatment of established tumors with a novel vaccine that enhances major histocompatibility class II presentation of tumor antigen. Cancer Res. 1996;56(1):21-6.

20. van Duikeren S, Fransen MF, Redeker A, Wieles B, Platenburg G, Krebber WJ, Ossendorp F, Melief CJ, Arens R. Vaccine-induced effector-memory CD8+ T cell responses predict therapeutic efficacy against tumors. J Immunol. 2012; 189(7):3397-403

21. Winzler C, Rovere P, Rescigno M, Granucci F, Penna G, Adorini L, Zimmermann VS, Davoust J, Ricciardi-Castagnoli P. Maturation stages of mouse dendritic cells in growth factor-dependent long-term cultures. J Exp Med. 1997;185(2):317-28.

22. Sanderson S, Shastri N. LacZ inducible, antigen/MHC-specific T cell hybrids. Int Immunol. 1994;6(3):369-76.

23. van der Sluis TC, Sluijter M, van Duikeren S, West BL, Melief CJ, Arens R, van der Burg SH, van Hall T. Therapeutic peptide vaccine-induced CD8 T cells strongly modulate Intratumoral macrophages required for tumor regression. Cancer Immunol Res. 2015;3(9):1042-51.

24. Feltkamp MC, Smits HL, Vierboom MP, Minnaar RP, de Jongh BM, Drijfhout JW, ter Schegget J, Melief CJ, Kast WM. Vaccination with cytotoxic T lymphocyte epitope-containing peptide protects against a tumor induced by human papillomavirus type 16-transformed cells. Eur J Immunol. 1993; 23(9):2242-9.

25. Zwaveling S, Ferreira Mota SC, Nouta J, Johnson M, Lipford GB, Offringa R, van der Burg SH, Melief CJ. Established human papillomavirus type 16expressing tumors are effectively eradicated following vaccination with long peptides. J Immunol. 2002;169(1):350-8.

26. Zom GG, Welters MJ, Loof NM, Goedemans R, Lougheed S, Valentijn RR, Zandvliet ML, Meeuwenoord NJ, Melief CJ, de Gruijl TD, et al. TLR2 ligandsynthetic long peptide conjugates effectively stimulate tumor-draining lymph node T cells of cervical cancer patients. Oncotarget. 2016;7(41): 67087-100.

27. Movahedi K, Laoui D, Gysemans C, Baeten M, Stange G, Van den Bossche J, Mack M, Pipeleers D, In't Veld P, De Baetselier P, et al. Different tumor microenvironments contain functionally distinct subsets of macrophages derived from Ly6C (high) monocytes. Cancer Res. 2010;70(14):5728-39.

28. Nakano H, Lin KL, Yanagita M, Charbonneau C, Cook DN, Kakiuchi T, Gunn MD. Blood-derived inflammatory dendritic cells in lymph nodes stimulate acute T helper type 1 immune responses. Nat Immunol. 2009;10(4):394-402.

29. Flo TH, Halaas O, Torp S, Ryan L, Lien E, Dybdahl B, Sundan A, Espevik T. Differential expression of toll-like receptor 2 in human cells. J Leukoc Biol. 2001;69(3):474-81

30. Ma Y, Adjemian S, Mattarollo SR, Yamazaki T, Aymeric L, Yang H, Portela Catani JP, Hannani D, Duret H, Steegh K, et al. Anticancer chemotherapyinduced intratumoral recruitment and differentiation of antigen-presenting cells. Immunity. 2013;38(4):729-41.

31. Kroemer G, Galluzzi L, Kepp O, Zitvogel L. Immunogenic cell death in cancer therapy. Annu Rev Immunol. 2013;31:51-72.

32. Welters MJ, van der Sluis TC, van Meir H, Loof NM, van Ham VJ, van Duikeren S, Santegoets SJ, Arens R, de Kam ML, Cohen AF, et al. Vaccination during myeloid cell depletion by cancer chemotherapy fosters robust T cell responses. Sci Transl Med. 2016;8(334):334ra352.

Ready to submit your research? Choose BMC and benefit from:

- fast, convenient online submission

- thorough peer review by experienced researchers in your field

- rapid publication on acceptance

- support for research data, including large and complex data types

- gold Open Access which fosters wider collaboration and increased citations

- maximum visibility for your research: over $100 \mathrm{M}$ website views per year

At $\mathrm{BMC}$, research is always in progress.

Learn more biomedcentral.com/submissions 